\title{
Effect of Angiotensin-Converting Enzyme Blockade, Alone or Combined With Blockade of Soluble Epoxide Hydrolase, on the Course of Congestive Heart Failure and Occurrence of Renal Dysfunction in Ren-2 Transgenic Hypertensive Rats With Aorto-Caval Fistula
}

\author{
P. KALA ${ }^{1,2}$, L. SEDLÁKOVÁ ${ }^{1}$, P. ŠKAROUPKOVÁ ${ }^{1}$, L. KOPKAN ${ }^{1}$, Z. VAŇOURKOVÁ ${ }^{1}$, \\ M. TÁBORSKÝ ${ }^{3}$, A. NISHIYAMA ${ }^{4}$, S. H. HWANG ${ }^{5}$, B. D. HAMMOCK ${ }^{5}$, J. SADOWSKI ${ }^{6}$, \\ V. MELENOVSKÝ ${ }^{7}$, J. D. IMIG ${ }^{8}$, L. ČERVENKA ${ }^{1,2}$
}

${ }^{1}$ Center for Experimental Medicine, Institute for Clinical and Experimental Medicine, Prague, Czech Republic, ${ }^{2}$ Department of Pathophysiology, Second Faculty of Medicine, Charles University, Prague, Czech Republic, ${ }^{3}$ Department of Internal Medicine I, Cardiology, University Hospital Olomouc and Palacký University, Olomouc Czech Republic, ${ }^{4}$ Department of Pharmacology, Kagawa University, Kagawa, Japan, ${ }^{5}$ Department of Entomology and UCD Cancer Center, University of California, Davis, CA, USA, ${ }^{6}$ Department of Renal and Body Fluid Physiology, Mossakowski Medical Research Centre, Polish Academy of Science, Warsaw, Poland, ${ }^{7}$ Department of Cardiology, Institute for Clinical and Experimental Medicine, Prague, Czech Republic, ${ }^{8}$ Department of Pharmacology and Toxicology, Medical College of Wisconsin, Milwaukee, WI, USA

Received September 7, 2017

Accepted January 5, 2018

On-line March 12, 2018

\section{Summary}

We showed recently that increasing kidney epoxyeicosatrienoic acids (EETs) by blocking soluble epoxide hydrolase (sEH), an enzyme responsible for EETs degradation, retarded the development of renal dysfunction and progression of aorto-caval fistula(ACF)-induced congestive heart failure (CHF) in Ren-2 transgenic hypertensive rats (TGR). In that study the final survival rate of untreated ACF TGR was only $14 \%$ but increased to $41 \%$ after $\mathrm{sEH}$ blockade. Here we examined if $\mathrm{SEH}$ inhibition added to renin-angiotensin system (RAS) blockade would further enhance protection against ACF-induced CHF in TGR. The treatment regimens were started one week after ACF creation and the followup period was 50 weeks. RAS was blocked using angiotensinconverting enzyme inhibitor (ACEi, trandolapril, $6 \mathrm{mg} / \mathrm{l}$ ) and $\mathrm{sEH}$ with an SEH inhibitor (sEHi, c-AUCB, $3 \mathrm{mg} / \mathrm{l}$ ). Renal hemodynamics and excretory function were determined two weeks post-ACF, just before the onset of decompensated phase of CHF. 29 weeks postACF no untreated animal survived. ACEi treatment greatly improved the survival rate, to $84 \%$ at the end of study.
Surprisingly, combined treatment with ACEi and SEHi worsened the rate (53\%). Untreated ACF TGR exhibited marked impairment of renal function and the treatment with ACEi alone or combined with $S E H$ inhibition did not prevent it. In conclusion, addition of sEHi to ACEi treatment does not provide better protection against CHF progression and does not increase the survival rate in ACF TGR: indeed, the rate decreases significantly. Thus, combined treatment with $\mathrm{SEHi}$ and ACEi is not a promising approach to further attenuate renal dysfunction and retard progression of CHF.

\section{Key words}

Congestive heart failure - Renal dysfunction - Hypertension • Aorto-caval fistula - Epoxyeicosatrienoic acids • Soluble epoxide hydrolase $\bullet$ Renin-angiotensin system

\section{Corresponding author}

L. Červenka, Center for Experimental Medicine, Institute for Clinical and Experimental Medicine, 1958/9 Vídeňská, 14000 Prague 4, Czech Republic. E-mail: luce@medicon.cz 


\section{Introduction}

Congestive heart failure (CHF) represents a serious public health problem with world-wide prevalence of $1-2 \%$ and the yearly increase in the number of new patients is estimated at $50 \%$ (Amborsy et al. 2014, Benjamin et al. 2017, Braunwald 2015, Roger 2013). Despite advances in the treatment, the survival rate of patients with CHF is below that for many common malignancies, especially in cases when CHF is associated with an impairment of renal hemodynamics and sodium retention (Braunwald 2015, Giamouzis et al. 2013, Ronco et al. 2008, Stewart et al. 2001). It is now recognized that renin-angiotensin system (RAS) plays a critical role in the pathophysiology of CHF, but also in the development of renal dysfunction in CHF, and in hypertension in general (Braam et al. 2014, Dube and Weber 2011, Hall et al. 2013, Ichikawa et al. 1984, Kobori et al. 2007, Moayedi et al. 2017, Packer and McMurray 2017, Patel et al. 2016, Re 2017, Rossi et al. 2017). Angiotensinconverting enzyme (ACE) blockade has become an integral component of the treatment of $\mathrm{CHF}$ and has beneficial long-term effects in experimental and clinical CHF, therefore, it is considered a golden standard therapy. However, its effectiveness in the advanced phase of CHF is limited (Brands et al. 1993, Brower et al. 2015, CONSENSUS Trial Study Group 1987, Červenka et al. 2015a, Červenka et al. 2015b, Ferrrario and Mullick 2017, McMurray et al. 2014, Pfeffer et al. 1985, Ponikowski et al. 2016, Ruzicka et al. 1994, SOLVD Investigators 1992, Yancy et al. 2017). Thus, despite a considerable progress in therapy and many treatment options available, the mortality in CHF remains high, and almost $50 \%$ of patients die within 5 years of the diagnosis. Evidently, new treatment strategies are urgently needed (Braunwald 2015, Ponikowski et al. 2016, Yancy et al. 2017), however, the prerequisite here is a better understanding of the pathophysiology of CHF. Therefore there is an obvious need for focused experimental studies that would evaluate the effects of new therapeutic approaches.

The rat with aorto-caval fistula (ACF) presents a well-defined model of CHF dependent on volume overload, characterized also by activation of the systemic and intrarenal RAS, signs of cardiac remodeling as well as congestion and impairment of renal function. Thus, in many aspects the model reproduces the course of CHF in untreated human patients (Abassi et al. 2011, Brower et al. 2015, Cohen-Segev et al. 2014, Červenka et al. 2015a,
Červenka et al. 2015b, Červenka et al. 2016, OliverDussault et al. 2010, Melenovský et al. 2010, Melenovský et al. 2011, Ruzicka et al. 1994, Sporková et al. 2017).

The hypertensive rat transgenic for the mouse Ren-2 renin gene [TGR; strain name TGR(mRen2)27] presents a unique angiotensin II (ANG II)-dependent model of hypertension in which its development is attributed to a single gene alteration and to the augmented activation of endogenous RAS (Kujal et al. 2010, Lee et al. 1990, Mullins et al. 1990). Thus, an experimental model of CHF that combines the well-recognized crucial detrimental factors promoting the progression of $\mathrm{CHF}$ is available and we have recently shown ACF TGR exhibit markedly increased CHF-related mortality as compared with the course in ACF Hannover Sprague-Dawley (HanSD) rats (transgene-negative, normotensive controls to TGR) (Červenka et al. 2015a, Červenka et al. 2016). We found that in addition to the increased RAS activity, ACF TGR also displayed tissue deficiency of biologically active fatty acid epoxides due to increased conversion of epoxyeicosatrienoic acids (EETs) [biologically active metabolites of cytochrome P450 (CYP)-dependent epoxygenase pathway of arachidonic acid (AA)] by soluble epoxide hydrolase (sEH) to biologically inactive dihydroxyeicosatrienoic acids (DHETEs). Indeed, increasing EETs in the kidney by pharmacological blockade of sEH markedly attenuated the development of renal dysfunction and progression of CHF in ACF TGR (Červenka et al. 2015a). In that study untreated ACF TGR exhibited the final survival rate of only $14 \%$ (the follow-up period was 50 weeks after induction of $\mathrm{ACF}$ ) and the pharmacological blockade of sEH alone significantly increased it to $41 \%$ (Červenka et al. 2015a). These findings suggest that pharmacological increasing EETs could be a novel tool for the treatment of CHF. However, it is important to recognize that we did not check if addition of sEH inhibition to the standard RAS blockade would exhibit additive beneficial effects on the mortality in TGR with ACF-induced CHF. Considering this limitation, we examined here whether the combined treatment with $\mathrm{sEH}$ inhibitor (sEHi) and ACEi will bring enhanced protection against CHF-dependent mortality as compared with the results achieved with ACEi treatment alone.

To further elucidate possible mechanisms underlying the expected additive beneficial action of combined SEH and ACE inhibition on the course of ACF-induced CHF, effects of 2-week treatments on renal 
function were assessed by renal clearance methods in separate groups of animals.

\section{Methods}

Ethical approval, animals, CHF model, and chronic treatments

The studies were performed in accordance with guidelines and practices established by the Animal Care and Use Committee of the Institute for Clinical and Experimental Medicine, Prague, and of the $2^{\text {nd }}$ Faculty of Medicine, Charles University, Prague, which accord with the European Convention on Animal Protection and Guidelines on Research Animal Use. All animals used in the present study were bred at the Center of Experimental Medicine of this Institute, which is accredited by the Czech Association for Accreditation of Laboratory Animal Care. Heterozygous TGR were generated by breeding male homozygous TGR with female homozygous transgene-negative normotensive Hannover Sprague-Dawley (HanSD) rats and age-matched HanSD rats served as controls. The animals were kept on a 12-hour/12-hour light/dark cycle. Throughout the experiments rats were fed a normal salt, normal protein diet $(0.45 \% \mathrm{NaCl}, 19-21 \%$ protein $)$ manufactured by SEMED (Prague, Czech Republic) and had free access to tap water.

Male TGR and HanSD rats, at the initial age of 8 weeks, derived from several litters, were randomly assigned to experimental groups to make sure that the animals from a single litter did not prevail in any group. In order to obtain reliable data regarding the effects of two treatment regimes on the survival rate, high initial $\mathrm{n}$ values were used (not so for sham-operated animals) to enable valid comparison of the long-term survival rate.

Rats were anesthetized (tiletamine + zolazepam, Virbac SA, Carros Cedex, France, $8 \mathrm{mg} / \mathrm{kg}$; and xylazine, Spofa, Czech Republic, $4 \mathrm{mg} / \mathrm{kg}$ intramuscularly) and CHF was induced by volume overload dependent on ACF created using needle technique as originally described by Garcia and Diebold (1990) and employed and validated by many investigators including our own group (Abassi et al. 2011, Brower et al. 2015, Cohen-Segev et al. 2014, Červenka et al. 2015a, Červenka et al. 2015b, Červenka et al. 2016, Oliver-Dussault et al. 2010, Melenovský et al. 2010, Melenovský et al. 2011, Ruzicka et al. 1994, Sporková et al. 2017). Briefly, after exposure of the abdominal aorta and inferior vena cava between the renal arteries and iliac bifurcation, the aorta was temporarily occluded at this segment for about $40 \mathrm{~s}$. An 18-gauge needle (diameter $1.2 \mathrm{~mm}$ ) was inserted into the abdominal aorta and advanced across its wall into the inferior vena cava to create ACF. Thereafter the needle was withdrawn and the puncture site was sealed with cyanoacrylate tissue glue. Successful creation of ACF was confirmed by inspection of pulsatile flow of oxygenated blood from the abdominal aorta into the vena cava. Sham-operated rats underwent an identical procedure but without creating ACF.

An inhibitor sEHi cis-4-[4-(3-adamantan-1-ylureido) cyclohexyloxy]benzoic acid (c-AUCB) was used, which was prepared freshly and given in drinking water at $3 \mathrm{mg} / \mathrm{l}$. The appropriate amount of $c$-AUCB was dissolved with gentle warming in polyethylene glycol and added with rapid stirring to warm drinking water to obtain a $0.1 \%$ aqueous solution of polyethylene glycol. The dose of $c$-AUCB was selected based on our recent studies where it elicited substantial increases in tissue concentration of EETs without altering RAS activity (Sporková et al. 2014). Based on the monitored water intake (once a week) the estimated daily dose of $c$-AUCB was $0.41 \pm 0.06 \mathrm{mg} \cdot \mathrm{kg}^{-1}$ of body weight and remained remarkably stable throughout the whole experiment. Similarly as in previous studies, we chose the $c$-AUCB dose that blocks sEH activity without altering plasma and tissue ANG II levels with an intention to separate and assess the effect of EETs elevation alone on the course of ACF-induced CHF. Trandolapril $(6 \mathrm{mg} / \mathrm{l}$ in drinking water; Gopten; Abbot, Prague, Czech Republic), was used to inhibit ACE because in our previous studies and here in preliminary experiments we demonstrated that at this dose the drug provided maximal blockade of RAS and was well tolerated both by rats with ACF-induced $\mathrm{CHF}$ and by sham-operated animals (Červenka et al. 2015a, Červenka et al. 2015b). The estimated daily dose of trandolapril was $0.82 \pm 0.07 \mathrm{mg} . \mathrm{kg}^{-1}$ of body weight and remained constant throughout the study. There were no significant difference in the water intake among experimental groups and therefore daily doses of $c$-AUCB and trandolapril were similar in all groups.

It was repeatedly reported that the present doses of sEHi and ACEi do not induce any toxic effects (Červenka et al. 2015a, Červenka et al. 2015b, El-Sherbeni et al. 2013, Fleming 2014, Moyadi et al. 2017, Ponikowski et al. 2016, Yancy et al. 2017). In addition, based on recent knowledge regarding properties of ACEi and sEHi, it is unlikely that their interaction would considerably change pharmacokinetic properties of 
ACEi and sEHi (Rugulski et al. 2015, Wagner et al. 2017). Moreover, based on this information it is also unlikely that drug elimination of ACEi and sEHi would be significantly altered in rats with ACF-induced $\mathrm{CHF}$ (Rugulski et al. 2015, Wagner et al. 2017).

Series 1: Effects of treatment with ACEi alone or combined with $S E H i$ on the survival rate

The rats underwent sham-operation or ACF creation as described above on the week labeled " -1 " and were left without treatment during 1 week. At this time point (week 0 ) the rats were divided into the following experimental groups:

Group 1: Sham-operated HanSD rats + placebo (initial $n=7$ )

Group 2: Sham-operated TGR + placebo (initial $n=9$ )

Group 3: ACF TGR + placebo (initial $n=32$ )

Group 4: ACF TGR + ACEi (initial $n=32$ )

Group 5: ACF TGR + ACEi + sEHi (initial n=36)

The follow-up period was the same as in our previous studies i.e. 50 weeks.

Series 1: Effects of 2-week treatment with ACEi alone or combined with sEHi on organ weights, blood pressure and renal hemodynamics and excretory function

Animals were prepared as described in series 1 and on week 0 the pharmacological treatment was initiated for a period of 2 weeks. At the end of the experimental protocol (on week +2 ), the rats were anesthetized and acute renal clearance experiments were performed to evaluate renal hemodynamics and excretory parameters as described in our previous studies (Červenka et al. 2015a, Červenka et al. 2015b, Honetschlagerová et al. 2011).

The following experimental groups were studied:

Group 1: Sham-operated HanSD rats + placebo $(n=12)$

Group 2: Sham-operated TGR + placebo (initial $n=10$ )

Group 3: ACF TGR + placebo (initial $n=11$ )

Group 4 ACF TGR + ACEi (initial $n=10$ )

Group 5: ACF TGR + ACEi + sEHi (initial n=10)

\section{Statistical analysis}

Statistical analysis of the data was performed using Graph-Pad Prism software (Graph Pad Software, San Diego, California, USA). Comparison of survival curves was performed by log-rank (Mantel-Cox) test followed by Gehan-Breslow-Wilcoxon test. Statistical comparison of other results was made by Student's $t$-test, Wilcoxon's signed-rank test for unpaired data or one-way
ANOVA when appropriate. Values are expressed as mean \pm S.E.M. and $\mathrm{n}$ represents the number of animals. $\mathrm{p}<0.05$ was considered statistically significant.

\section{Results}

Series 1: Effects of treatment with ACEi alone or combined with $S E H i$ on the survival rate

All sham-operated HanSD rats survived until the end of the experiment. One sham-operated TGR unpredictably died 25 weeks after sham-operation, all the others survived until the end of experiment. It will be noticed that this single death resulted in a profound decrease in mean survival rate: the final survival rate was $89 \%$. However, this was the consequence of relatively low $\mathrm{n}$ value in this group. It must also be admitted that in the present study we did not perform autopsies of died animals, an obvious drawback because we cannot make any clear conclusion regarding the reason for the death of animals in any of experimental groups.

As shown in Figure 1, untreated ACF TGR began to die in week 2 (i.e. 3 weeks after induction of ACF) and all the animals died by week 29. The treatment with ACEi substantially increased the survival rate, to $84 \%$ at the end of study as compared with untreated ACF TGR $(p<0.05)$. The combined treatment with sEHi and ACEi also improved the survival rate throughout the experiment (the final survival rate was $53 \%$ ) as compared with untreated ACF TGR $(\mathrm{p}<0.05)$, however, the actual rate was significantly lower than observed in ACF TGR treated with ACEi alone $(\mathrm{p}<0.05)$.

Series 1: Effects of 2-week treatment with ACEi alone or combined with sEHi on organ weights, blood pressure and renal hemodynamics and excretory function

As shown in Figures 2A and 2B, sham-operated TGR exhibited significant cardiac hypertrophy [expressed as whole heart weight (HW) to tibia length (TL) ratio], with marked left ventricle (LV) hypertrophy [expressed as LV weight (LVW) to tibia length (TL)] as compared with sham-operated HanSD rats $(\mathrm{p}<0.05)$. Untreated ACF TGR showed marked increases in HW/TL as well as in LVW/TL as compared with sham-operated TGR $(p<0.05)$. The treatment with ACEi alone as well as the combined treatment with $\mathrm{SEH}$ inhibitor and ACEi significantly lowered $\mathrm{HW} / \mathrm{TL}$ as well as LVW/TL to values observed in sham-operated TGR. Figure $2 \mathrm{C}$ shows that there were no significant differences in right ventricle (RV) weight [expressed as RV weight (RVW) 
to TL] between sham-operated HanSD rats and sham-operated TGR. Untreated ACF TGR showed striking increases in RVW/TL as compared with shamoperated TGR (indicating the development of marked
RV cardiac hypertrophy) $(\mathrm{p}<0.05)$. Both treatment regimes significantly and to a similar degree decreased RVW/TL in ACF TGR.

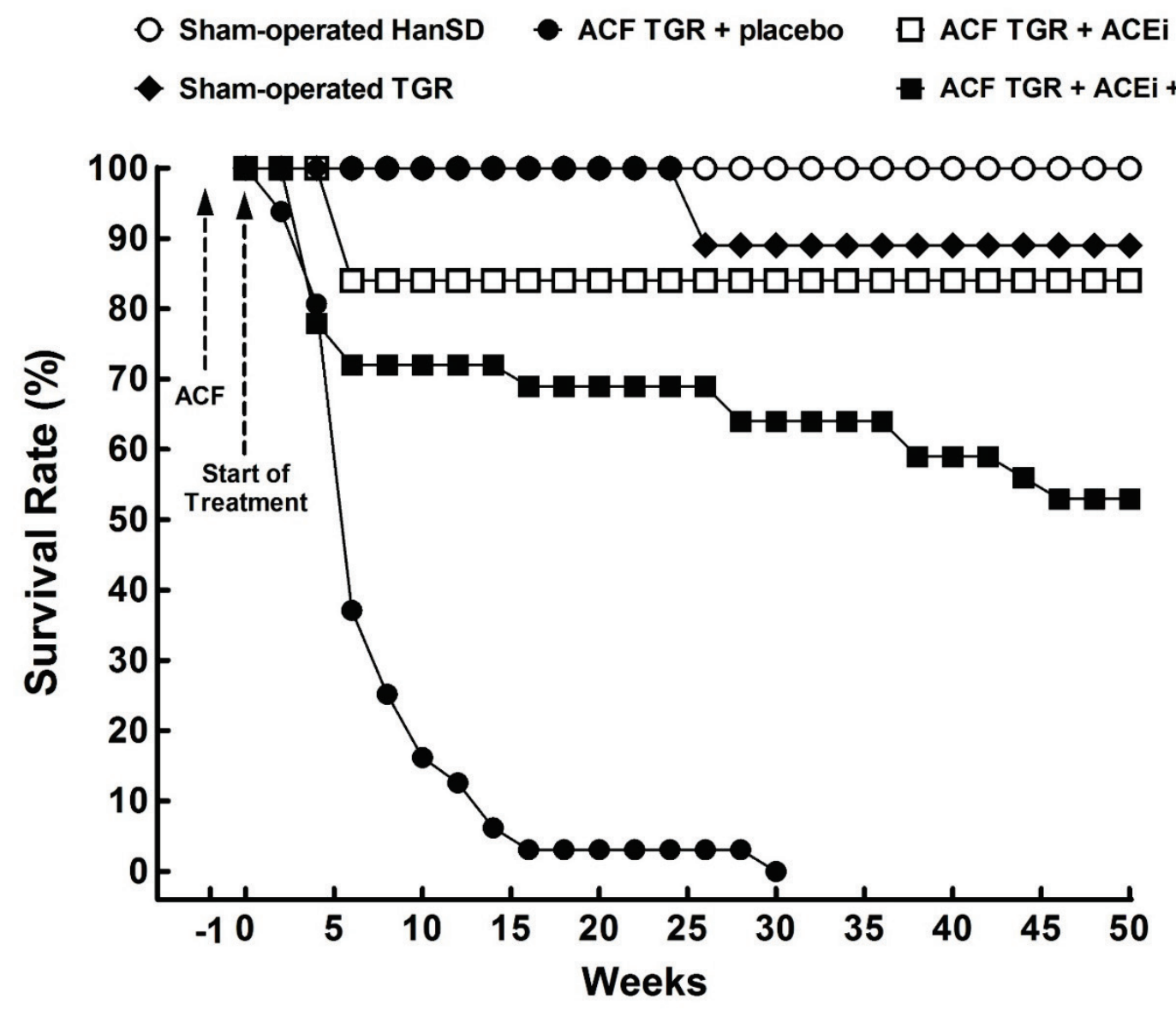

Fig. 1. Survival rates in sham-operated transgene-negative Hannover Sprague-Dawley (HanSD) and sham-operated heterozygous Ren-2 transgenic rats (TGR), in untreated TGR with aorto-caval fistula (ACF TGR + placebo), in ACF TGR treated with angiotensinconverting enzyme inhibitor (ACF TGR + ACEi) and in ACF TGR treated with the combination of angiotensin-converting enzyme inhibitor and soluble epoxide hydrolase inhibitor (ACF TGR + ACEi + SEHi). The survival rate curve in ACF TGR + placebo was significantly lower compared to those in the other groups. Both treatments significantly improved the survival rate curve, however the best results were observed in ACF TGR + ACEi + sEHi group (log-rank Mantel-Cox test followed by Gehan-Breslow-Wilcoxon test).

As shown in Figure 3A, untreated ACF TGR displayed significantly higher ratio of lung weight to TL as compared with sham-operated HanSD rats as well as sham-operated TGR (indicating the development of important lung congestion in ACF TGR) ( $p<0.05$ in all cases). The treatment with ACEi alone as well as the combined treatment with sEHi and ACEi significantly lowered this ratio in ACF TGR, but it still remained significantly higher than in sham-operated TGR $(\mathrm{p}<0.05)$.

There were no significant differences between experimental groups in liver and kidney weight when normalized to TL (Figs 3B and 3C).
As shown in Figure 4A, sham-operated TGR were markedly hypertensive as compared with shamoperated HanSD rats $(\mathrm{p}<0.05)$. Untreated ACF TGR showed significantly lower mean arterial pressure (MAP) as compared with sham-operated TGR, but it still remained higher than MAP values in sham-operated HanSD rats $(p<0.05)$. The treatment with ACEi alone as well as the combined treatment with sEHi and ACEi significantly lowered MAP in ACF TGR as compared with their untreated counterparts and the values of MAP were even significantly lower than in sham-operated HanSD rats $(\mathrm{p}<0.05)$. 
A
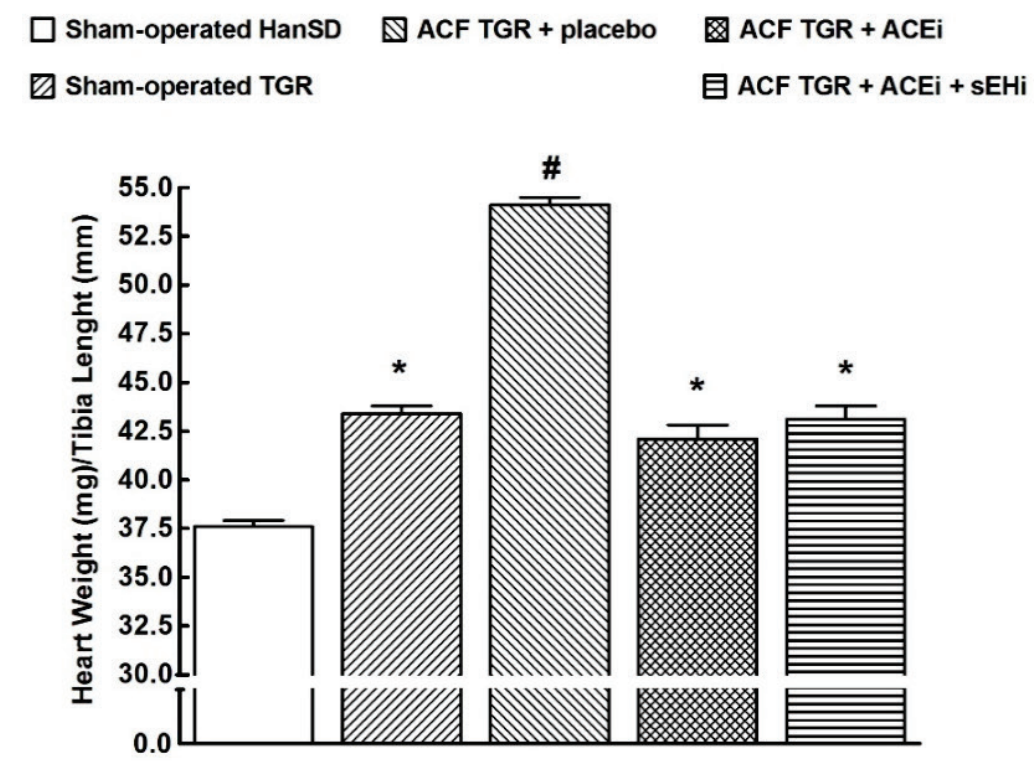

B

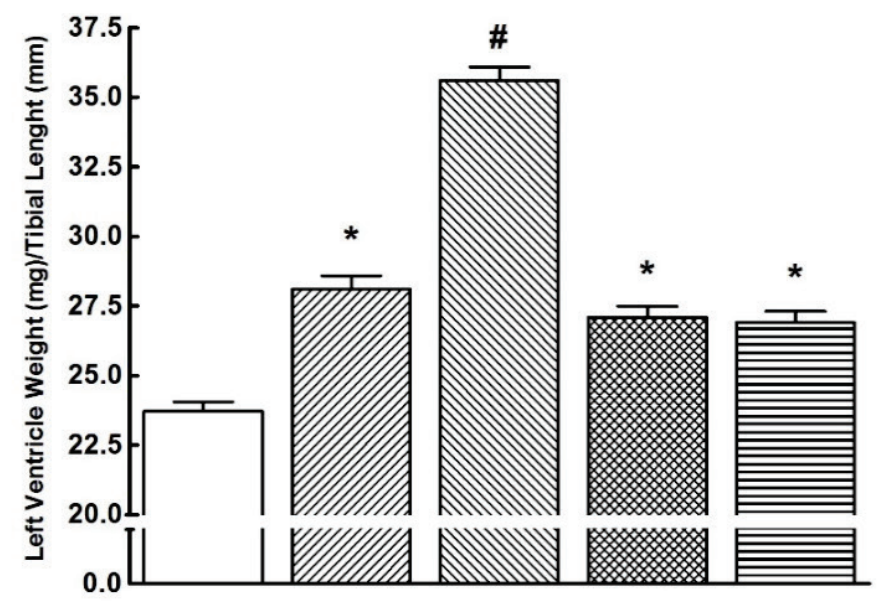

C

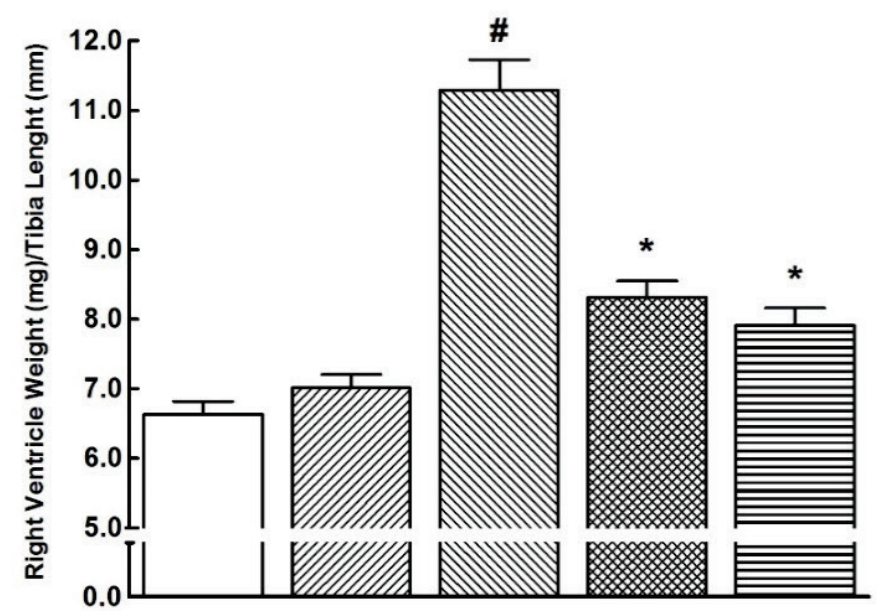

Fig. 2. Whole heart weight (A), left ventricle weight (B) and right ventricle weight (C) normalized to tibia length in sham-operated transgene-negative Hannover Sprague-Dawley (HanSD) and sham-operated heterozygous Ren-2 transgenic rats (TGR), in untreated TGR with aorto-caval fistula (ACF TGR + placebo), in ACF TGR treated with angiotensin-converting enzyme inhibitor (ACF TGR + ACEi) and in ACF TGR treated with the combination of angiotensin-converting enzyme inhibitor and soluble epoxide hydrolase inhibitor (ACF TGR + ACEi $+\mathrm{sEHi}) . * \mathrm{p}<0.05$ compared with sham-operated HanSD. ${ }^{\#} p<0.05$ compared with all the other groups.
There were no significant differences in renal blood flow (RBF) between sham-operated HanSD rats and sham-operated TGR (Fig. 4B). Untreated ACF TGR exhibited significantly lower $\mathrm{RBF}$ as compared with sham-operated TGR $(\mathrm{p}<0.05)$. The treatment with ACEi alone as well as the combined treatment with sEHi and ACEi did not significantly change RBF in ACF TGR. There were no significant differences in the glomerular filtration rate (GFR) between experimental groups (Fig. 4C). 
A

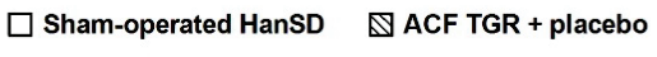
$\square$ Sham-operated TGR

$\otimes A C F T G R+A C E i$

目 $A C F$ TGR + ACEi + sEHi

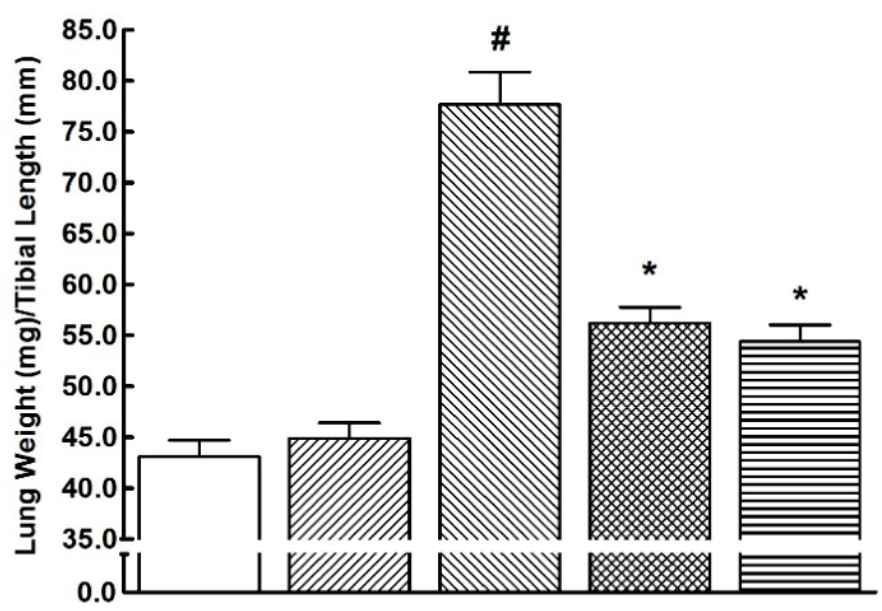

B

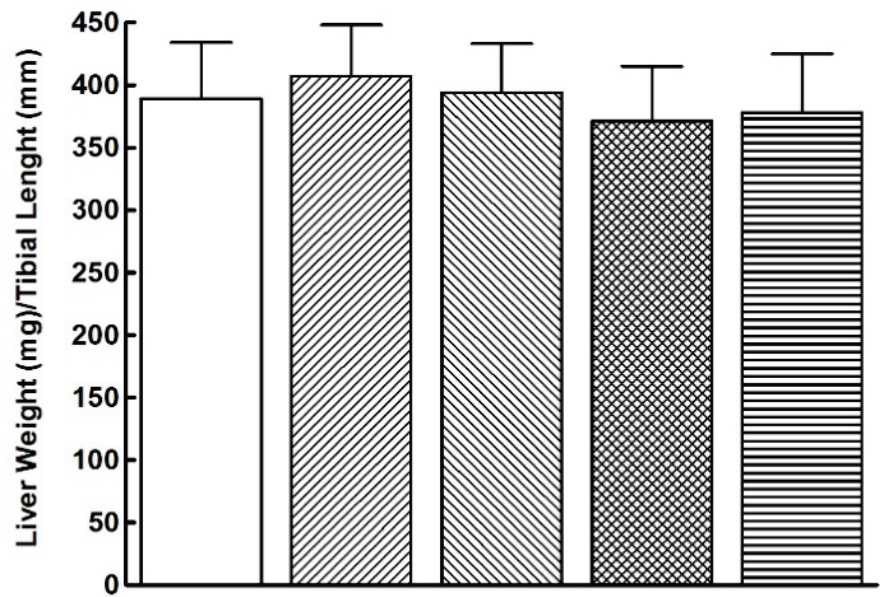

C

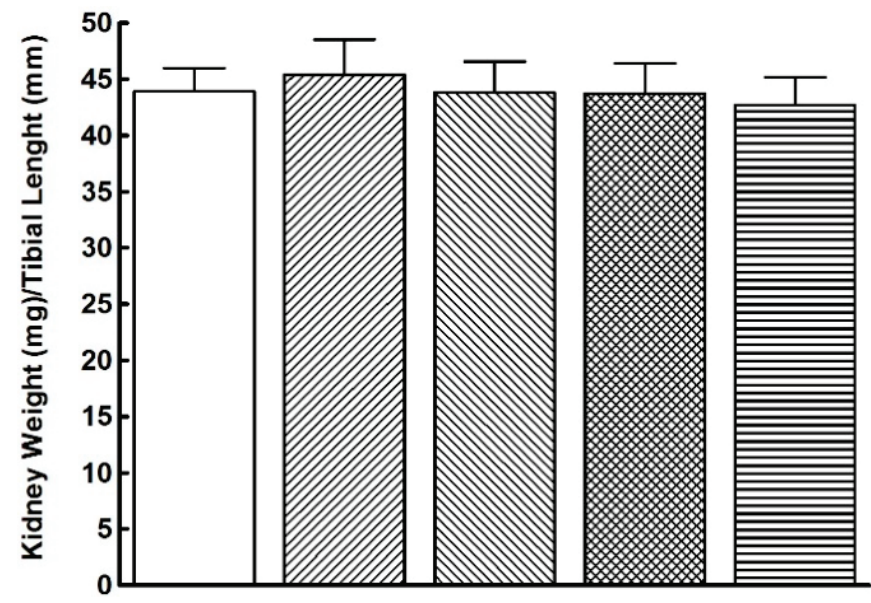

Fig. 3. Lung weight (A), liver weight (B) and kidney weight (C) normalized to tibia length in sham-operated transgene-negative Hannover Sprague-Dawley (HanSD) and shamoperated heterozygous Ren- 2 transgenic rats (TGR), in untreated TGR with aorto-caval fistula (ACF TGR + placebo), in ACF TGR treated with angiotensin-converting enzyme inhibitor (ACF TGR + ACEi) and in ACF TGR treated with the combination of angiotensinconverting enzyme inhibitor and soluble epoxide hydrolase inhibitor (ACF TGR + ACEi + sEHi). $* p<0.05$ compared with sham-operated HanSD. ${ }^{\#} p<0.05$ compared with all other groups.
Figures 5A, 5B and 5C show that untreated ACF TGR displayed substantially lower urine flow and absolute and fractional sodium excretion as compared with sham-operated HanSD rats and sham-operated TGR $(\mathrm{p}<0.05$ in all cases). The treatment with ACEi alone or the combined treatment with sEHi and ACEi did not normalize any of these parameters in ACF TGR. 
A

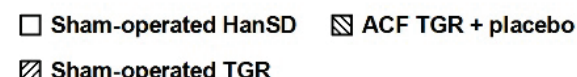

$\square$ Sham-operated TGR

ACF TGR + ACEi

目 ACF TGR + ACEi + sEHi

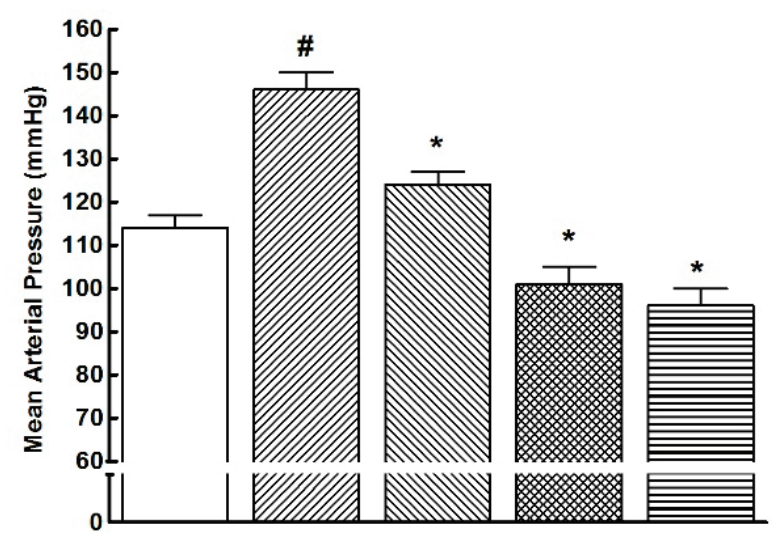

B

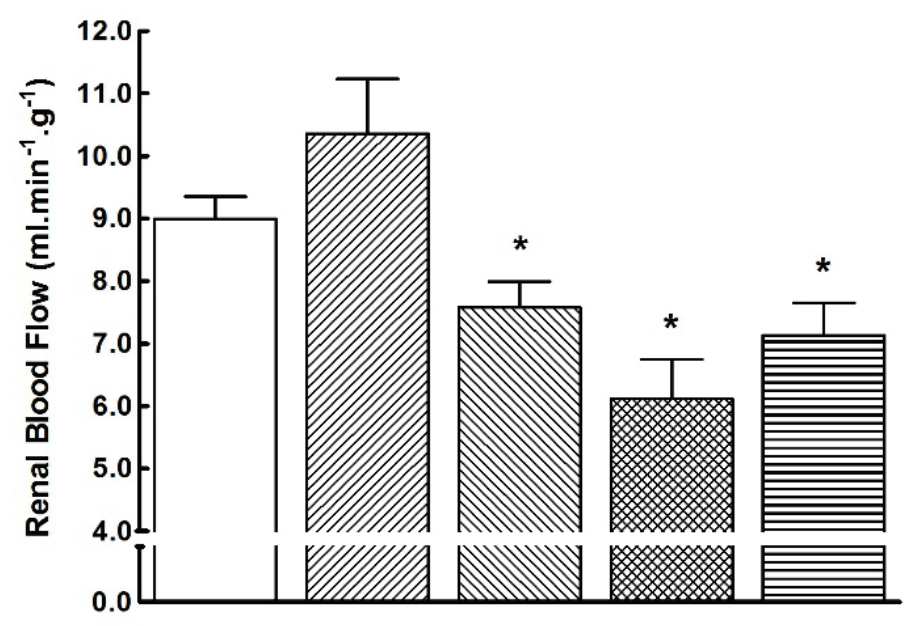

C

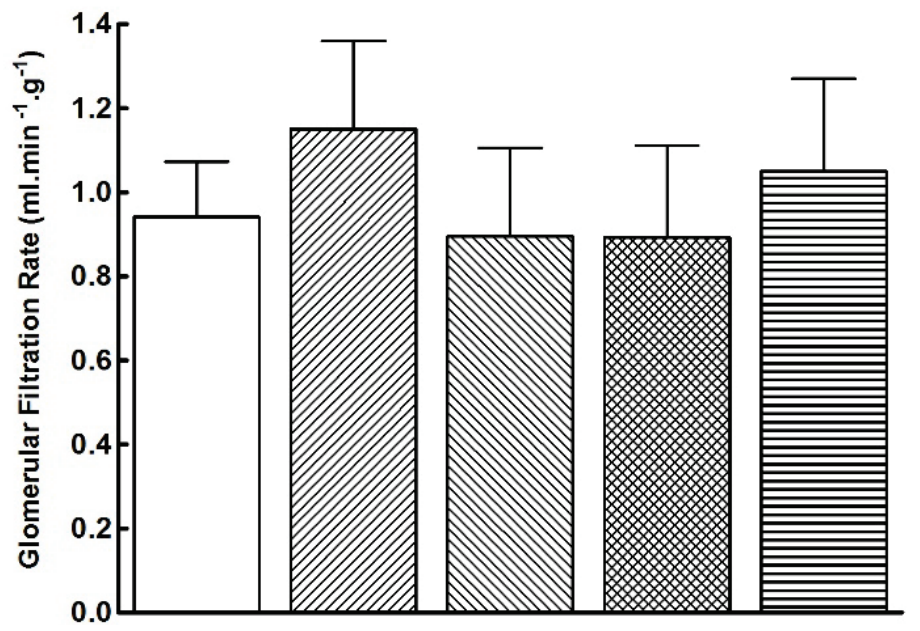

Fig. 4. Mean arterial pressure (A), renal blood flow (B) and glomerular filtration rate (C) in sham-operated transgene-negative Hannover Sprague-Dawley (HanSD) and sham-operated heterozygous Ren-2 transgenic rats (TGR), in untreated TGR with aorto-caval fistula (ACF TGR + placebo), in ACF TGR treated with angiotensinconverting enzyme inhibitor (ACF TGR + ACEi) and in ACF TGR treated with the combination of angiotensin-converting enzyme inhibitor and soluble epoxide hydrolase inhibitor (ACF TGR + ACEi + $\mathrm{sEHi).} * \mathrm{p}<0.05$ compared with shamoperated HanSD. ${ }^{*} p<0.05$ compared with all the other groups.

\section{Discussion}

The crucial finding of this study is that addition of sEH blockade to standard ACEi therapy did not improve the survival rate and did not attenuate the development of renal dysfunction in ACF TGR. Surprisingly, the combined treatment worsened the survival rate as compared with ACF TGR treated with ACEi alone. These findings deserve special attention for several reasons. 
A

$\begin{array}{lll}\square \text { Sham-operated HanSD } & \mathbb{Q} \text { ACF TGR + placebo } & \text { 冈 ACF TGR + ACEi } \\ \square \text { Sham-operated TGR } & \text { 目 ACF TGR + ACEi + sEHi }\end{array}$

B
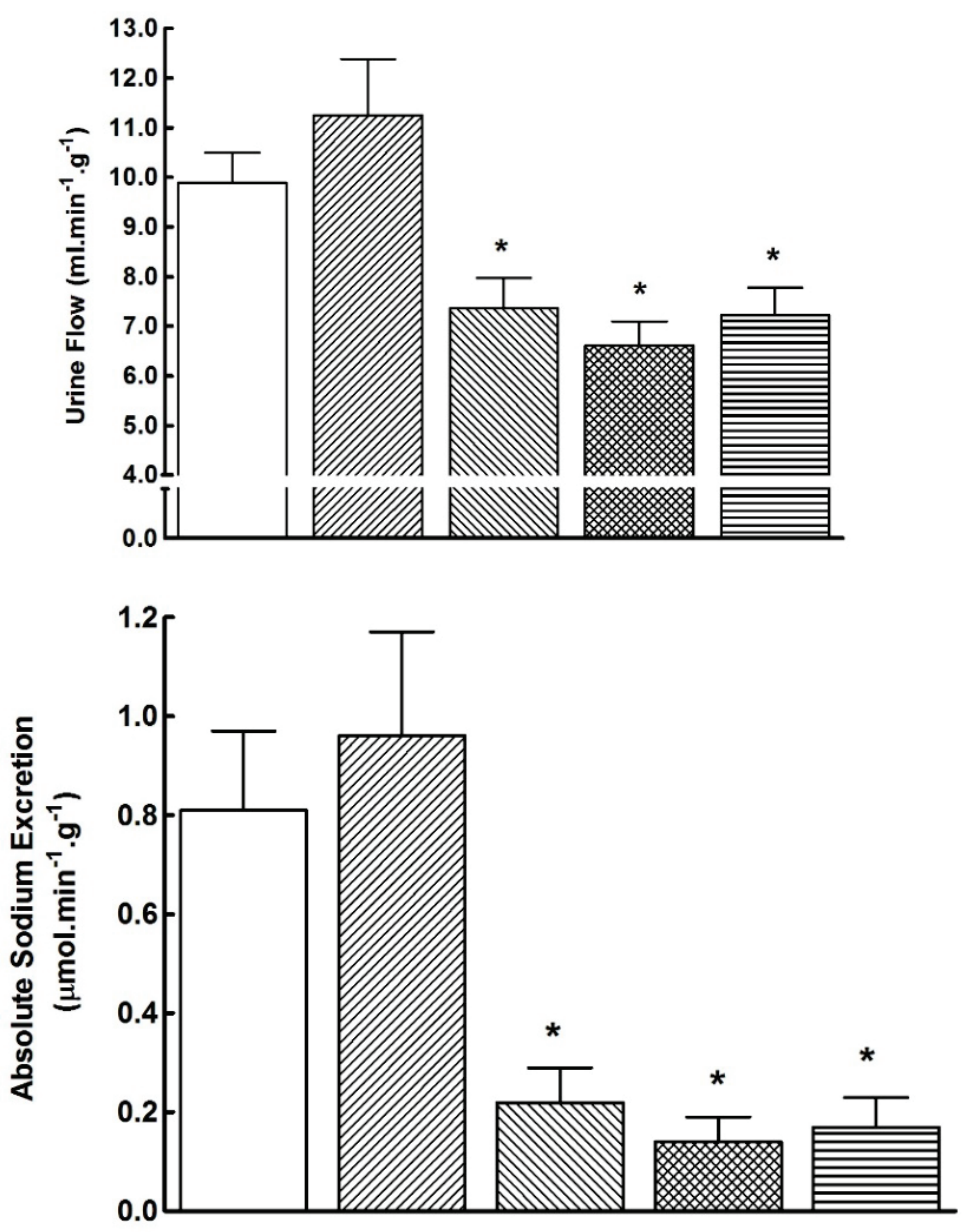

C

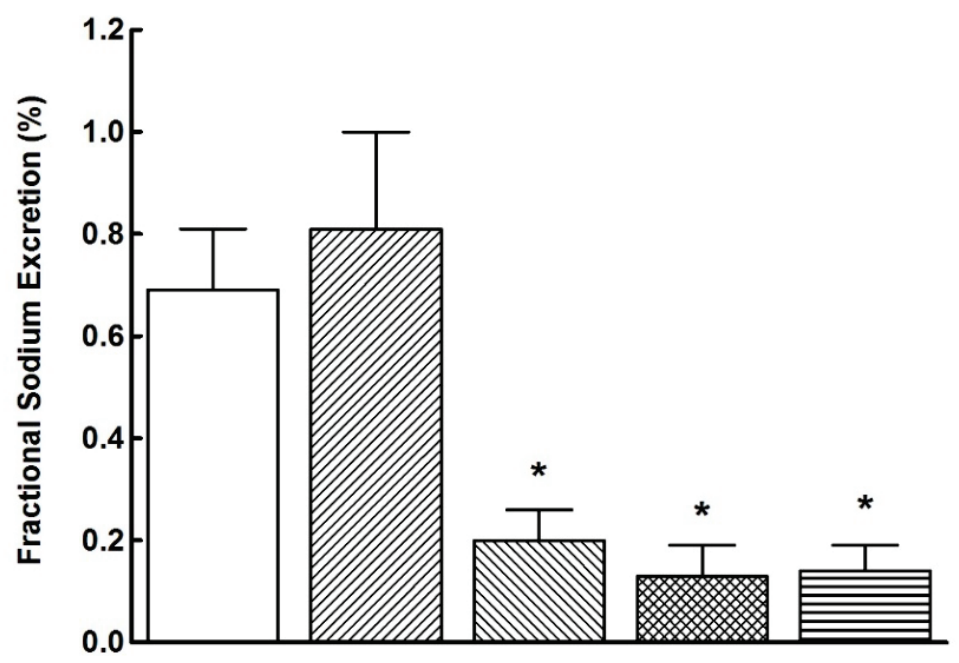

Fig. 5. Urine flow (A), absolute sodium excretion (B) and fractional sodium excretion (C) in sham-operated transgene-negative Hannover SpragueDawley (HanSD) and sham-operated heterozygous Ren-2 transgenic rats (TGR), in untreated TGR with aorto-caval fistula (ACF TGR + placebo), in ACF TGR treated with angiotensin-converting enzyme inhibitor (ACF TGR + ACEi) and in ACF TGR treated with the combination of angiotensin-converting enzyme inhibitor and soluble epoxide hydrolase inhibitor (ACF TGR + ACEi $+\mathrm{sEHi}$ ). $* p<0.05$ compared with sham-operated HanSD.
It is noteworthy that as soon as three weeks after induction of ACF untreated ACF TGR displayed signs of marked cardiac hypertrophy accompanied by lung congestion (indicating LV heart failure) without symptoms of RV failure (no liver congestion). These findings indicate that already by this time untreated ACF TGR were in the transition stage from the compensated to decompensated heart hypertrophy and heart failure, which was also reflected by the onset of CHF-dependent mortality. This is remarkable because we 
and others have reported that in normotensive animals at least 10 weeks after induction of ACF-induced volume overload are required before the development of CHF symptoms (Abassi et al. 2011, Beneš et al. 2011, Brower et al. 1996, Brower et al. 2015, Červenka et al. 2015a, Červenka et al. 2015b, Červenka et al. 2016, Hutchinson et al. 2011, Oliver-Dussault et al. 2010, Melenovský et al. 2010, Melenovský et al. 2011, Wang et al. 2003) and the first deaths occur usually around the $20^{\text {th }}$ week. Moreover, in our original study that characterized the course of CHF-related morbidity and mortality in the same model of normotensive rats we found a median survival of 43 weeks after ACF induction (Melenovský et al. 2012). Thus, our present results strengthen the evidence that hypertension and markedly activated RAS are two critical features promoting progression of $\mathrm{CHF}$ to the fatal end.

Furthermore, it was seen that already three weeks after induction of ACF untreated ACF TGR displayed marked impairment of renal hemodynamics and renal sodium excretion, which agrees with the observation that in patients with CHF the development of renal dysfunction is associated with markedly increased risk of death (Braam et al. 2014, Giamouzis et al. 2013, Re 2017, Ronco et al. 2008). Moreover, the present results further support our earlier findings suggesting that persistent renal dysfunction rather than progressing cardiac remodeling is responsible for the reduction of long-term survival rate in ACF-induced model of CHF. Indeed, it appeared that in this model predominantly renal mechanisms determine the beneficial effects of the treatments which delay the decompensation of CHF (Červenka et al. 2015a, Červenka et al. 2015b). However, it is emphasized that in ACF TGR the development of renal dysfunction is accelerated compared with normotensive animals, which again supports the notion on the negative effects of hypertension and inappropriately activated RAS on the course of CHF (Braam et al. 2014, Dube and Weber 2011, Moayedi et al. 2017, Packer and McMurray 2017, Patel et al. 2016, Re 2017, Rossi et al. 2017).

Admittedly, a limitation of our present study is that we did not evaluate cardiac function. However, when cardiac function had been evaluated by echocardiography and pressure-volume analyses (Červenka et al. 2015a), we found that creation of ACF in TGR resulted after 5 weeks in the development of marked eccentric chamber remodeling and cardiac hypertrophy related to increased cardiac output: the consequence of blood recirculation through the fistula. At this stage untreated ACF TGR showed significantly suppressed slope of end-systolic pressure-volume relationship and decreased LV fractional shortening, which indicated important systolic dysfunction as compared with sham-operated TGR. In addition, untreated ACF TGR also displayed prolonged $\mathrm{LV}$ relaxation along with decreased end-diastolic pressure-volume relationship, which indicated impairment of early diastolic function with a simultaneous enhancement of end-diastolic chamber compliance. However, the critically important finding of this study was that the 5-week treatment with sEHi or ACEi did not change any of those cardiac parameters in ACF TGR, which indicated that the improvement of survival rate was not related to the beneficial effects on cardiac function but rather to the attenuation of the development of renal dysfunction in this model (Červenka et al. 2015a).

All these facts considered, in contrast to our recent study (Červenka et al. 2015a), we did not find beneficial effects of the treatment with ACEi, alone or combined with $\mathrm{sEHi}$, on RBF and renal excretory function. This was entirely unexpected; we do not have satisfactory explanation for these surprising findings and it is obvious that further studies are needed to address this issue.

We found that chronic treatment with ACEi dramatically improved the survival rate in ACF TGR, which again confirms the view on the crucial role of the RAS in the pathophysiology of CHF, and wide agreement on pharmacological blockade of the RAS by ACE inhibition being the first-line treatment in CHF (CONSENSUS Trial Study Group 1987, Ferrrario and Mullick 2017, McMurray et al. 2014, Pfeffer et al. 1985, Ponikowski et al. 2016, SOLVD Investigators 1992, Yancy et al. 2017). Nevertheless, even though the effectiveness of ACEi treatment was relatively high in the advanced phase of CHF, the treatment did not prevent the development of renal dysfunction and CHF-related mortality was still significant, which further underscores the need to search for new pharmacological strategies that would prevent renal dysfunction and progression of $\mathrm{CHF}$ to the fatal end.

In this connection, the critically important question is why the combined treatment with sEHi and ACEi did not enhance protection against CHF-dependent mortality but even worsened it as compared to the ACF TGR treated with ACEi alone. To this we have no satisfactory explanation: our hypothesis was that 
combining the two treatments, each affecting different vasoactive system, should enhance the effectiveness in delaying or even preventing decompensation in CHF. The hypothesis was based on the strong evidence, provided by ourselves and others, indicating that ACF model of CHF is characterized by marked activation of vasoconstrictor/sodium retaining axis and suppression of vasodilatory/natriuretic axis of the intrarenal RAS, and by profound intrarenal deficiency of biologically active epoxy fatty acids (the result of increased sEH-mediated conversion of EETs to DHETEs) (Abassi et al. 2011, Cohen-Segev et al. 2014, Červenka et al. 2015a, Červenka et al. 2015b). In addition, we showed recently that treatment with sEHi alone and ACEi alone (the same drugs at the same doses as used in the present study) exhibited clear beneficial effects on the course of CHF in ACF TGR, (Červenka et al. 2015a). Importantly, the beneficial effects of chronic sEH inhibition with $c$-AUCB were accompanied by normalization of tissue availability of EETs, without altering intrarenal concentrations of ANG II and angiotensin-1-7 (ANG 1-7). Dissimilarly, protective effects of chronic treatment with ACEi were associated with significant suppression of the intrarenal vasoconstrictor/sodium retaining axis of the RAS (reflected by profound decreases in ANG levels) and activation of the intrarenal vasodilatory/natriuretic axis (reflected by increases in ANG 1-7 concentrations), without modifying tissue EETs. Collectively, these data provided robust evidence which encouraged testing our original hypothesis that the combined treatment with SEHi and ACEi should bring enhanced beneficial effects on the course of CHF. Surprisingly, this was not the case, and for unknown reasons the survival rate even decreased. An appropriately focused study, rather than undue speculation, would be needed to address this issue. However, we feel that at least one aspect deserves attention now.

It will be noticed that both SEHi and ACEi exhibit important blood pressure (BP)-lowering effects, related to the increased intrarenal EETs and their vasodilatory and natriuretic actions (sEHi) (Elmarakby 2012, Fleming 2014, Imig 2015) or to the intrarenal blockade of the RAS activity (ACEi) (GonzalezVillalobos et al. 2013, Hall et al. 2013, Kobori et al. 2007). Therefore, the combined treatment could in the long term exhibit additive BP-lowering effects, perhaps bringing BP below renal autoregulation range (Carlstrom and Wilcox 2015). This could per se impair renal function in ACF TGR and thereby increase CHF-related mortality in this model. However, our current data show that the MAP value observed after two weeks of combined treatment $(96 \pm 3 \mathrm{~mm} \mathrm{Hg})$ did not significantly differ from that recorded in rats receiving ACEi alone $(101 \pm 3 \mathrm{~mm} \mathrm{Hg}, \mathrm{p}>0.05)$. In either case MAP remained within the range of effective renal blood flow autoregulation. To achieve more meaningful comparative data, comprehensive long term studies are needed that would evaluate BP measured by radiotelemetry in conscious animals. Unfortunately, relatively short durability of implanted telemetric probes limits at present the plausibility of such prolonged experiments. In general, one should be fully aware that CHF combined with kidney damage is a very complex disease running with multiple combined pathophysiological processes. This requires extreme caution in applying complex treatment, and careful adjustment of the dosage of individual drugs, thus, there is a need for more research of pathophysiology of CHF combined with renal dysfunction. The studies should also address the puzzle of deterioration of the beneficial effects of ACEi treatment when the treatment with sEHi is added.

Given that ACEi alone or combined with sEHi did not attenuate the development of renal dysfunction but still significantly attenuated CHF-related mortality, one should also consider other mechanisms that could be responsible for this beneficial effect. Since ACEi alone as well as the combined treatment significantly lowered MAP in ACF TGR, a role of a lowering of the afterload should be considered, especially in view of the evidence on a relationship between lung congestion and the degree of afterload in CHF (Abassi et al. 2011, Braunwald 2015, Oliver-Dussault et al. 2010). Indeed, our findings show that both treatment regimes significantly lowered the degree of lung congestion in ACF TGR. Again, it is apparent that future studies are needed to address this hypothesis.

In conclusion, we found that addition of sEHi to ACEi treatment did not provide better protection against CHF progression or increased the survival rate in ACF TGR, indeed, the rate decreased significantly. Thus, increasing tissue EETs in individuals with pharmacologically-induced suppression of the RAS does not at present seem to be a promising approach to further attenuate renal dysfunction and progression of CHF, at least as studied in the model used here.

\section{Conflict of Interest}

There is no conflict of interest. 


\section{Acknowledgements}

This study was primarily supported by the Ministry of Health of the Czech Republic grant no. 17-28220A awarded to M. Táborský. All rights reserved. L. Červenka was also supported by Ministry of Health of the Czech Republic within the project for the development of research organization 00023001 (IKEM)-institutional support. This work was also partially supported by a National Institute of Health grant (DK103616) to John D. Imig. Partial support was supplied by NIEHS R01 ES002710 and Superfund Research Program P42 ES004699 awarded to Bruce D. Hammock. Peter Kala is M.D. student who is supported by the Grant Agency of Charles University (GAUK), project number 32218 .

\section{References}

ABASSI Z, GOLTSMNA I, KARRAM T, WINAVER J, HOFFMAN A: Aortocaval fistula in rat: a unique model of volume-overload congestive heart failure and cardiac hypertrophy. J Biomed Biotechnol 2011: 729497, 2011.

AMBROSY AP, FONAROW GC, BUTLER J, CHIONCEL O, GREENE SJ, VADUGANATHAN M, NODARI S, LAM CS, SATO N, SHAH AN, GHEORGHIADE M: The global health and economic burden of hospitalizations for heart failure: lessons learned from hospitalized heart failure registries. $J$ Am Coll Cardiol 63: 1123-1133, 2014.

BENES J, KAZDOVA L, DRAHOTA Z, HOUSTEK J, MEDRIKOVA D, KOPECKY J, KOVAROVA N, VRBACKY M, SEDMERA D, STRNAD H, KOLAR M, PETRAK J, BENADA O, SKAROUPKOVA P, CERVENKA L, MELENOVSKY V: Effect of metformin therapy on cardiac function and survival in a volume-overload model of heart failure in rats. Clin Sci 129: 29-41, 2011.

BENJAMIN EJ, BLAHA MJ, CHIUVE SE, CUSHMAN M, DAS SR, DE FERRANTI SD, FLOYD J, FORNAGE M, GILLESPIE C, ISASI CR, JIMÉNEZ MC, JORDAN LC, JUDD SE, LACKLAND D, LICHTMAN JH, ET AL.: Heart disease and stroke statistics-2017 update: a report from the American Heart Association. Circulation 135: e146-e603, 2017.

BRAMM B, JOLES JA, DANISWAR AH, GAILLARD CA: Cardiorenal syndrome - current understanding and future perspectives. Nat Rev Nephrol 10: 48-55, 2014.

BRANDS MW, ALONSO-GALICIA M, MIZELLE HL, MONTANI JP, HILDEBRANDT DA, HALL JE: Chronic angiotensin-converting-enzyme inhibition improves cardiac output and fluid balance during heart failure. Am J Physiol 264: R414-R422, 1993.

BRAUNWALD E: The war against heart failure. Lancet 385: 812-824, 2015.

BROWER GL, HENEGAR JR, JANICKI JS: Temporal evaluation of left ventricular remodeling and function in rats with chronic volume overload. Am J Physiol 40: H2071-H2078, 1996.

BROWER GL, LEVICK SP, JANICKI JS: Differential effects of prevention and reversal treatment with Lisinopril on left ventricular remodeling in a rat model of heart failure. Heart Lung Circ 24: 919-924, 2015.

CARLSTROM M, WILCOX CS, ARENDHORST WJ: Renal autoregulation in health and disease. Physiol Rev 95: 405-511, 2015.

COHEN-SEGEV R, FRANCIS B, ABU-SALEH N, AWAD H, LAZAROVICH A, KABALA A, ARONSON D, ABASSI Z: Cardiac and renal distribution of ACE and ACE-2 in rats with heart failure. Acta Histochem 116: 1342-1349, 2014.

CONSENSUS TRIAL STUDY GROUP: Effects of enalapril on mortality in severe congestive heart failure. Results of the Cooperative North Scandinavian Enalapril Survival Study (CONSENSUS). N Engl J Med 316: 1429-1435, 1987.

ČERVENKA L, MELENOVSKÝ V, HUSKOVÁ Z, ŠKAROUPKOVÁ P, NISHIYAMA A, SADOWSKI J: Inhibition of soluble epoxide hydrolase counteracts the development of renal dysfunction and progression of congestive heart failure in Ren-2 transgenic hypertensive rats with aorto-caval fistula. Clin Exp Pharmacol Physiol 42: 795-807, 2015a. 
ČERVENKA L, MELENOVSKÝ V, HUSKOVÁ Z, SPORKOVÁ A, BURGELOVÁ M, ŠKAROUPKOVÁ P, HWANG SH, HAMMOCK BD, IMIG JD, SADOWSKI J: Inhibition of soluble epoxide hydrolase does not improve the course of congestive heart failure and the development of renal dysfunction in rats with volume overload induced by aorto-caval fistula. Physiol Res 64: 857-873, 2015b.

ČERVENKA L, ŠKAROUPKOVÁ P, KOMPANOWSKA-JEZIERSKA E, SADOWSKI J: Sex-linked differences in the course of chronic kidney disease and congestive heart failure: a study in 5/6 nephrectomized Ren-2 transgenic hypertensive rats with volume overload using aorto-caval fistula. Clin Exp Pharmacol Physiol 43: 883-895, 2016.

DUBE P, WEBER KT: Congestive heart failure: pathophysiologic consequences of neurohormonal activation and the potential for recovery: part I. Am J Med Sci 342: 348-351, 2011.

ELMARAKBY AA: Reno-protective mechanisms of epoxyeicosatrienoic acids in cardiovascular disease. Am J Physiol Regul Integr Comp Physiol 302: R321-R330, 2012.

EL-SHERBENI AA, ABOUTABL ME, ZORDOKY BN, ANWAR-MOHAMED A, EL-KADI AO: Determination of the dominant arachidonic acid cytochrome P450 monooxygenase in rat heart, lung, kidney, and liver: protein expression and metabolite kinetics. AAPS J 15: 112-122, 2013.

FLEMING I: The pharmacology of the cytochrome P450 epoxygenase/soluble epoxide hydrolase axis in the vasculature and cardiovascular disease. Pharmacol Rev 66: 1106-1140, 2014.

FERRARIO CM, MULLICK AE: Renin angiotensin aldosterone inhibition in the treatment of cardiovascular disease. Pharmacol Res 125: 57-71, 2017.

GARCIA R, DIEBOLD S: Simple, rapid, and effective method of producing aortocaval shunts in the rat. Cardiovasc Res 24: 430-432, 1990.

GIAMOUZIS G, KALOGEROUPOULOS AP, BUTLER J, KARAYANNIS G, GEORGIOPOULOU VV, SKOULARIGIS J, TRIPOSKIADIS F: Epidemiology and importance of renal dysfunction in heart failure patients. Curr Heart Fail Rep 10: 411-420, 2013.

GONZALEZ-VILLALOBOS RA, JANJOULIA T, FLETCHER NK, GIANI JF, NGUYEN MT, RIQUIER-BRISON AD, SETH DM, FUCHS S, ELADARI D, PICARD N, BACHMANN S, DELPIRE E, PETI-PERDI J, NAVAR LG, BERNSTEIN KE, MCDOUNOUGH AA: The absence of intrarenal ACE protects against hypertension. J Clin Invest 123: 2011-2023, 2013.

HALL JE, GRANGER JP, HALL ME: Physiology and pathophysiology of hypertension. In: Seldin and Giebisch's The Kidney: Physiology And Pathophysiology, Fifth Edition. ALPERN RJ, CAPLAN MJ, MOE OW (eds), Academic Press, 2013, pp 1319-1352.

HONETSCHLAGEROVÁ Z, SPORKOVÁ A, KOPKAN L, HUSKOVÁ Z, HWANG SH, HAMMOCK BD, IMIG JD, KRAMER HJ, KUJAL P, VERNEROVÁ Z, ČERTÍKOVÁ CHÁBOVÁ V, TESAŘ V, ČERVENKA L: Inhibition of soluble epoxide hydrolase improves the impaired pressure-natriuresis relationship and attenuates the development of hypertension and hypertension-associated end-organ damage in Cyp1a1-Ren-2 transgenic rats. J Hypertens 29: 1590-1601, 2011.

HUTCHINSON KR, GUGGILAM A, CISMOWSKI MJ, GALANTOWICS ML, WEST TA, STEWART JA JR, ZHANG X, LORD KC, LUCCHESI PA: Temporal pattern of left ventricular structural and functional remodeling following reversal of volume overload heart failure. J Appl Physiol 111: 1778-1788, 2011.

ICHIKAWA I, PFEFFER JM, PFEFFER MA, HOSTETTER TH, BRENNER BM: Role of angiotensin II in the altered renal function of congestive heart failure. Circ Res 55: 669-675, 1984.

IMIG JD: Epoxyeicosatrienoic acids, hypertension, and kidney injury. Hypertension 65: 476-482, 2015.

KOBORI H, NANGAKU M, NAVAR LG, NISHIYAMA A: The intrarenal renin-angiotensin system: from physiology to the pathobiology of hypertension and kidney disease. Pharmacol Rev 59: 251-287, 2007.

LEE MA, BOHM M, PAUL M, BADER M, GANTEN U, GANTEN D: Physiological characterization of the hypertensive transgenic rat TGR(mRen2)27. Am J Physiol 270: E919-E929, 1990. 
MCMURRAY JJ, PACKER M, DESAI AS, GONG J, LEFKOWITZ MP, RIZKALA AR, ROULEAU JL, SHI VC, SOLOMON SD, SWEDBERG K, ZILE MR, PARADIGM-HF INVESTIGATORS AND COMMITEES: Angiotensin-neprilysin inhibition versus enalapril in heart failure. N Engl J Med 371: 993-1004, 2014.

MELENOVSKY V, BENES J, SKAROUPKOVA P, SEDMERA D, STRNAD H, KOLAR M, VLCEK C, PETRAK J, BENES J JR, PAPOUSEK F, OLIYARNYK O, KAZDOVA L, CERVENKA L: Metabolic characterization of volume overload heart failure due to aorto-caval fistula in rats. Mol Cell Biochem 354: 83-96, 2011.

MELENOVSKY V, SKAROUPKOVA P, BENES J, TORRESOVA V, KOPKAN L, CERVENKA L: The course of heart failure development and mortality in rats with volume overload due to aorto-caval fistula. Kidney Blood Press Res 35: 167-173, 2012.

MOYEDI Y, ROSS HJ: Advances in heart failure: a review of biomarkers, emerging pharmacological therapies, durable mechanical support and telemonitoring. Clin Sci 131: 553-566, 2017.

MULLINS JJ, PETERS J, GANTEN D: Fulminant hypertension in transgenic rat harboring the mouse Ren-2 gene. Nature 344: 541-544, 1990.

OLIVER-DUSSAULT C, ASCAH A, MARCIL M, MATAS J, PICARD S, PIBAROT P, BURELLE Y, DESCHEPPER CF: Early predictors of cardiac decompensation in experimental volume overload. Mol Cell Biochem 338: 271-281, 2010.

PACKER M, MCMURRAY JJV: Importance of endogenous compensatory vasoactive peptides in broadening the effects of inhibitors of the renin-angiotensin system for the treatment of heart failure. Lancet 389: 1831-1840, 2017.

PATEL VB, ZHONG JC, GRANT MB, OUDIT GY: Role of the ACE2/angiotensin 1-7 axis of the renin-angiotensin system in heart failure. Circ Res 118: 1313-1326, 2016.

PFEFFER MA, PFEFFER JM, STEINBERG C, FINN P: Survival after an experimental myocardial infarction: beneficial effects of long-term therapy with captopril. Circulation 72: 406-412, 1985.

RE RN: A reassessment of the pathophysiology of progressive cardiorenal disorders. Med Clin North Am 101: 103-115, 2017.

PONIKOWSKI P, VOORS AA, ANKER SD, BUENO H, CLELAND JG, COATS AJ, FALK V, GONZÁLEZJUANATEY JR, HARIOLA VP, JAKOWSKA EA, JESSUP M, LINDE C, NIHOANNOPOULOS P, PARISSIS JT, PIESKE B, ET AL.: 2016 ESC Guidelines for the diagnosis and treatment of acute and chronic heart failure: The Task Force of the diagnosis and treatment of acute and chronic heart failure of the European Society of Cardiology (ESC) Developed with the special contribution of the Heart Failure Association (HFA) of the ESC. Eur Heart J 37: 2129-2200, 2016.

REGULSKI M, REGULSKA K, STANISZ BJ, MURIAS M, GIEREMEK P, WZGARDA A, NIZNIK B: Chemistry and pharmacology of angiotensin-converting enzyme inhibitors. Curr Pharm Des 21: 1764-1775, 2015.

ROGER VL: Epidemiology of heart failure. Circ Res 113: 646-659, 2013.

RONCO C, HAAPIO M, HOUSE AA, AVAVEKAR N, BELLOMO R: Cardiorenal syndrome. J Am Coll Cardiol 52: 1527-1539, 2008.

ROSSI F, MASCOLO A, MOLLACE V: The pathophysiological role of natriuretic peptide-RAAS cross talk in heart failure. Int J Cardiol 226: 121-125, 2017.

RUZICKA M, YUAN B, LEENEN FHH: Effects of enalapril versus losartan on regression of volume overload-induced cardiac hypertrophy in rats. Circulation 90: 484-491, 1994.

SOLVD INVESTIGATORS, YUSUF S, PITT B, DAVIS CE, HOOD WB JR, COHN JN: Effect of enalapril on mortality and the development of heart failure in asymptomatic patients with reduced left ventricular ejection fractions. N Engl J Med 327: 658-691, 1992.

SPORKOVÁ A, HUSKOVÁ Z, ŠKAROUPKOVÁ P, REDDY NR, FALCK JR, SADOWSKI J, ČERVENKA L: Vasodilatory responses of renal interlobular arteries to epoxyeicosatrienoic acids analog are not enhanced in Ren-2 transgenic hypertensive rats: evidence against a role of direct vascular effects of epoxyeicosatrienoic acids in progression of experimental heart failure. Physiol Res 66: 29-39, 2017. 
SPORKOVA A, JÍCHOVÁ Š, HUSKOVÁ Z, KOPKAN L, NISHIYAMA A, HWANG SH, HAMMOCK BD, IMIG JD, KOMPANOWSKA-JEZIERSKA E, SADOWSKI J, KRAMER HJ, CERVENKA L: Different mechanism of acute versus long-term antihypertensive effects of soluble epoxide hydrolase inhibition: studies in Cyp1a1Ren-2 transgenic rats. Clin Exp Pharmacol Physiol 41: 1003-1013, 2014.

STEWART S, MACINTYRE K, HOLE DJ, CAPEWELL S, MCMURRAY JJV: More "malignant" than cancer? Five year survival following a first admission for heart failure. Eur J Heart Fail 3: 315-322, 2001.

YANCY CW, JESSUP M, BOZKURT B, BUTLER J, CASEY DE, COLVIN MM, DRAZNER MH, FILIPATOS GS, FONAROW GC, GIVERTZ MM, HOLLENBERG SM, LINDEFELD J, MASOUDI FA, MCBRIDE PE, PETERSON PN, STEVENSON LW, WESTLAKE C: 2017 ACC/AHA/HFSA focused update of the 2013 ACCF/AHA Guideline for the management of heart failure. Circulation 136: e137-e161, 2017.

WAGNER KM, MCREYNOLDS CB, SCHMIDT WK, HAMMOCK BD: Soluble epoxide hydrolase as a therapeutic target for pain, inflammatory and neurodegenerative diseases. Pharmacol Ther 180: 62-76, 2017.

WANG X, REN B, LIU S, SENTEX E, TAPPIA PS, DHALLA NS: Characterization of cardiac hypertrophy and heart failure due to volume overload in the rat. $J$ Appl Physiol 94: 752-763, 2003. 